\title{
A SEASONAL BREAKAGE OF MAINSPRINGS IN WATCHES
}

\author{
By S. R. WILLIAMS,
}

\section{Oberitin College, Obertin, Ohio.}

There seem to exist in every trade certain beliefs and notions, which are not always supported by scientific principles. It may be recalled that blacksmiths have an idea that if the redhot end of an iron bar is suddenly plunged into water, while the other end is held in the hand, that the smith can notice a very rapid and perceptible increase in temperature of the portion. held in his hand. In other words, they believe that the water very suddenly drives the heat from the hot end to the cooler one. Curiously enough, careful investigation of this idea was made by two departments of physics of leading universities of this country and quite independently could not find, by means of sensitive instruments, the changes which the blacksmiths seem to pretty generally recognize.

Again, there is a belief among many barbers that a thundershower dulls their razors and that special attention must be paid to sharpening them after the thunder and lightening.

These beliefs held by various trades should not be put in the same class with the superstitions held by many of our professional baseball players, as to the effectiveness of a rabbit's foot or some other talisman in bringing success to their playing.

It is well to remind ourseives that a blacksmith named Arstall, once conceived the idea that an iron rod would change its length, if magnetized. He spoke to Joule, a prominent physicist of England, about it, who became sufficiently interested in the suggestion to test it and found, indeed, that such was the case, although an extremely small increment of length occurred when the magnetic field was applied.

While the explanations offered by the trades for their ideas are not always supported by scientifie reasons, there are fundamental principles back of them which show why they persist in the minds of those who believe in them. For instance, in the case of the iron rod whose heated end is suddenly plunged into cold water, in all probability steam arises from the water where the heated rod enters it and this steam ascending envelops the hand grasping the other end and gives the sensation of a sudden increase of temperature. At any rate the ideas are frequently worthy of further investigation as the following may well illustrate.

Enquiry among a number of those engaged in the business 
of watch repairing reveals a persistent notion that the electricity present during a thunder shower is accountable for a large number of mainsprings snapping during and immediately following a thundershower. This would mean that a maximum number of mainsprings would be broken during the summer months. The practice of jewelers to record all replacements of mainsprings makes the study of a possible seasonal breakage

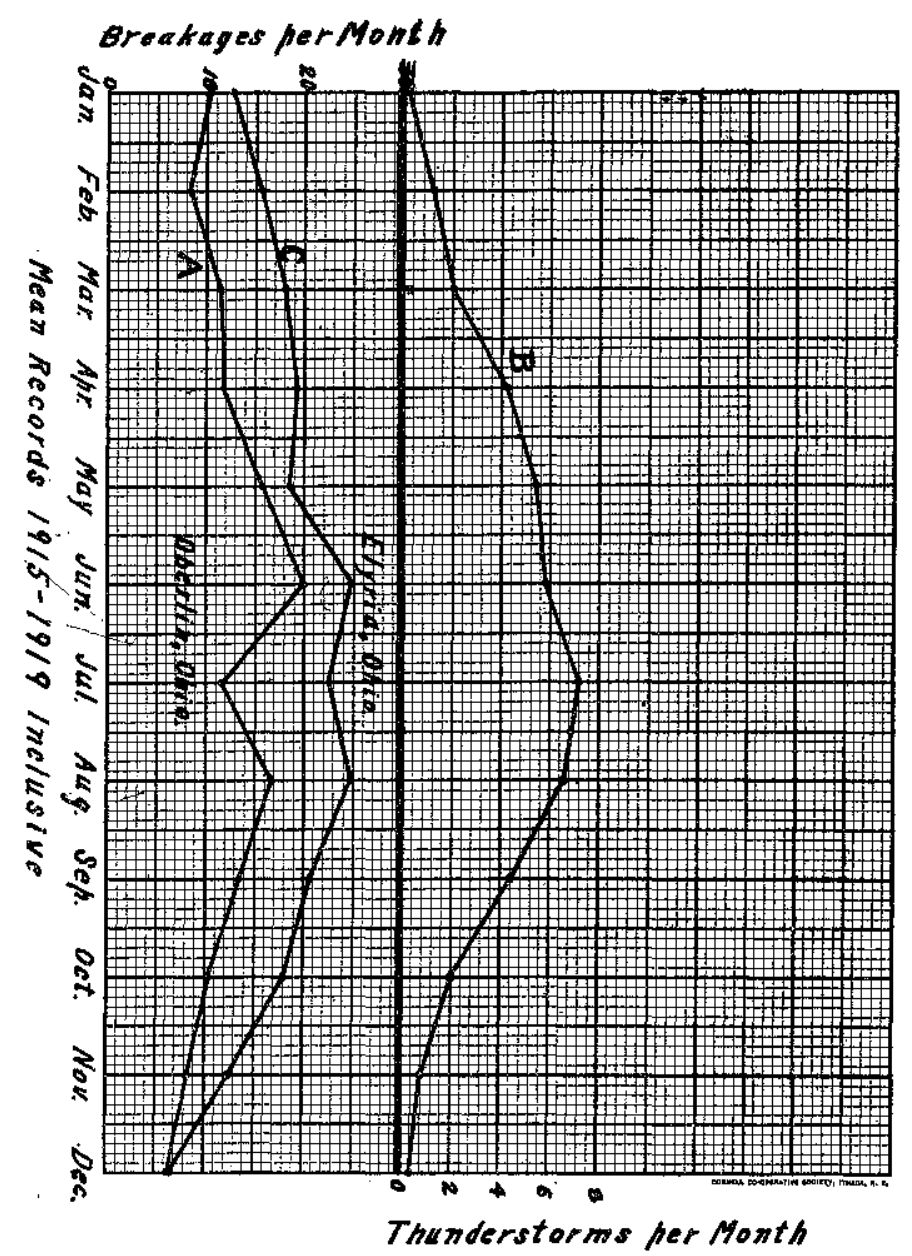

FIG. 1.

of watch-springs a very easy one, if we may take as a criterion of the number of springs broken, the number which are brought to the jeweler for replacement. 
To ascribe this breakage to electricity may be ruled out at once for the mainsprings are coiled in a metal barrel, which in turn is inside of a metal case and the combination makes absolute protection against any electrical disturbances. Magnetic effects were looked for but none could be discoverd.

Through the courtesy of Messrs. Herrick and Shreffler of Oberlin, Ohio, and Mr. Chas. H. Savage of Elyria, Ohio, they allowed a search of their records to be made and the number of mainsprings replaced each month was recorded over a continuous period of five years, 1915, '16, '17, '18 and '19. The average number replaced each month for the period of five years was then plotted as ordinates and the time in months as abscissa. In curve A, Fig. 1 , is shown the composite curve for the five years as taken from the records of Messrs Herrick and Shreffer, while curve B, Fig. 1, shows the average number of thunder-showers per month over the same five years as were taken for curve A. Oberlin is a college town of about 4,300 inhabitants, to which is added for nine months of the year a student population of 2,000 from the middle of September until about the middle of June. A large percentage of Oberlin's population is away for the summer so we may expect a dropping off of replacements during July, which is the month most of the people go away for a vacation. In Fig. 1, curve $\mathrm{C}$ shows a similar study from the records of Mr. Savage of Elyria, Ohio. This town has a population of more than 20,000 and the number of inhabitants remains much more constant during the twelve months than does Oberlin. Even in curve C, Fig. 1, there is shown a drop in the breakage during July which may be aseribed to the vacation habit. That is, people are not at home during July to have their watches repaired.

The data from which curve B, Fig. 1, was plotted was obtained from the weather reports for Cleveland, Ohio, as that was the weather bureau station, nearest to Oberlin and Elyria, reporting thunder-showers. There seems to be a real connection between these curves plotted in Fig. 1. If electricity and magnetism are not the causes, what is? Moisture is the obvious answer and so the next study was an experimental one, in which the breakage of pieces of watchsprings under tension was observed when they were in a moist atmosphere and when they were in a dry one. The results seem very conclusive and were carried out by Mr. Herman Seemann, an advanced student in the department of Physics. 


\section{Mr. Semmann's Exf'eriments.}

A watchspring was cut into pieces about five centimeters long, each alternate piece being thrown in one pile and the others in another pile. These were put in a state of strain by bending them in a small loop and holding the ends together by a clamping device, Fig. 2. One set of springs was then placed in a jar in which a vessel of water was located and the other set of springs was placed in a similar jar but with a vessel of calcium chloride present to keep the air inside the jar dry, Fig. 3. Both jars were sealed airtight so that the jars remained, one with a saturated atmosphere and the other with a dry atmosphere. These were observed for a period of cime and the number which broke in each jar was recorded. The results of a number of different tests are given in-

$\begin{array}{ccccc}\text { Exp. No. } & \begin{array}{c}\text { Samples in } \\ \text { each jar. }\end{array} & \begin{array}{c}\text { Table } \\ \text { Days under } \\ \text { observation. }\end{array} & \begin{array}{c}\text { No. broken in } \\ \text { dry air. }\end{array} & \begin{array}{c}\text { No.broken in } \\ \text { moist air }\end{array} \\ 1 & 22 & 7 & 0 & 11 \\ 2 & 28 & 52 & 0 & 17 \\ 3 & 30 & 41 & 0 & 10\end{array}$

These are not selected sets of observations but were all of the observations which were made on this particular point. That moisture is not the important factor can hardly be argued.

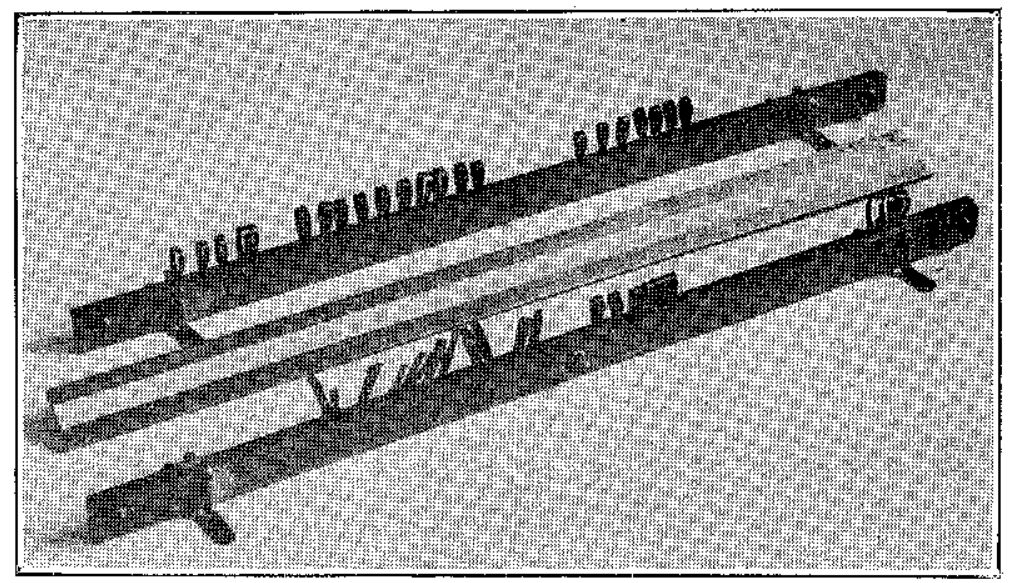

Fig. 2.

Corrrespondence with a number of large watch manufacturers of the country showed that they held very different views about a seasonal breakage of watchsprings. One thought that if a seasonal breakage did occur it would give a maximum in the winter because, "people foolishly wound their watches 
at night after taking them off of their warm bodies and then laying them down on a dresser or bureau where they cooled off and the mainspring contracting made the tension too great and the spring would break. Naturally this would occur most in the winter when the extremes of temperature would occur." Others thought that the maximum would occur in the summer

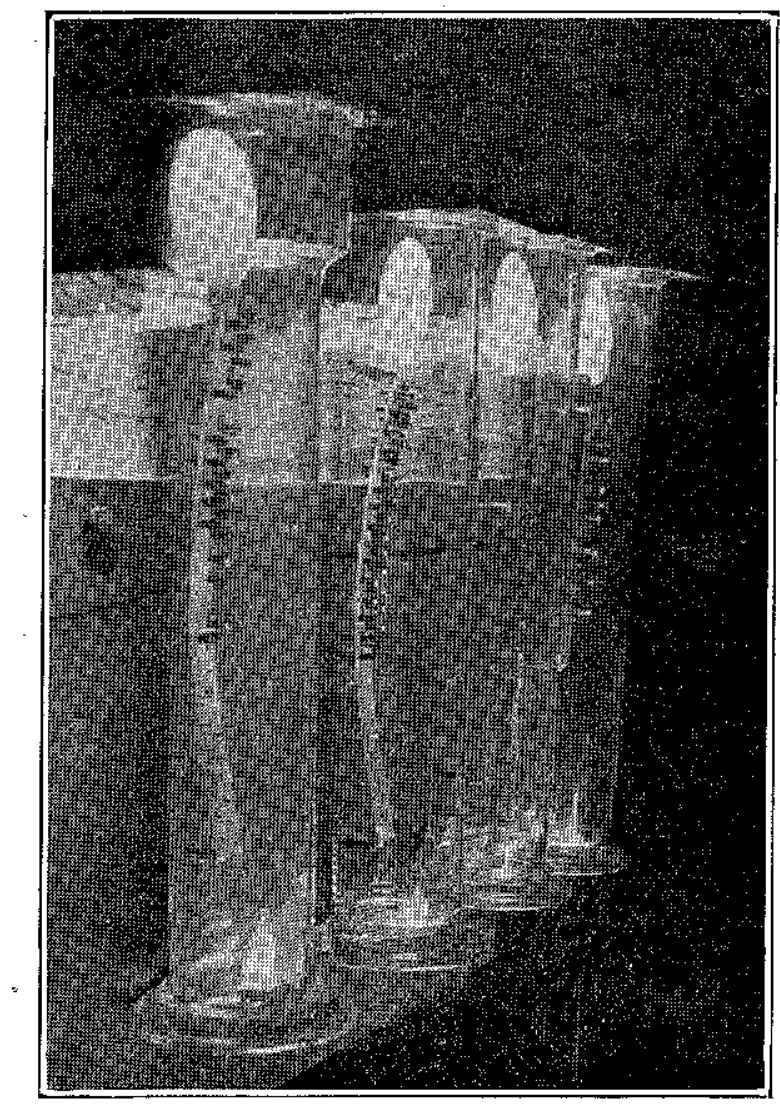

Fig. 3 .

but that it would depend on the hardness of the springs used. In table 1 it is to be noted that the springs used were quite different in character and yet the experiments were all carried out in the laboratory which had a fairly constant temperature at the time the experiments were carried out. As one manufacturer wrote, "no scientific tests had been made to ascertain whether atmospheric conditions are the cause of this breakage or not." 
Moisture therefore seems to be the main cause of the seasonal breakage. Investigation of the springs under a compound microscope showed minute rust spots at the points where the springs had broken indicating that moisture had promoted rusting there and which had broken the skin effect of the spring. How powerful this skin effect in metals is, was shown by an earlier experience of the author; the rotating table, on which the disc records of a talking machine are laid, is trimmed up in a lathe on an arbor. In trimming up such a table the top surface was taken off and the heavy cast-iron plate curled down in the form of a steel helmet and that in spirte of the trussed form on the bottom of the disc. Once a crack starts the rust works into the fissure causing still greater weakness of the spring at that point and it finally breaks under the tension under which it is placed.

Temperature accelerates the process of oxidation. A group of these pieces of spring under tension, as already described, were placed in a saturated atmosphere and tested at different temperatures for a period of more than fourteen days. It was found that at a range of $37^{\circ}-39^{\circ} \mathrm{C}$., more springs broke than at an average temperature of $18^{\circ} \mathrm{C}$. The temperatures at these two limits were controlled by thermostats.

A careful study of the breakage of railroad rails ${ }^{t}$ on the Harriman lines over a period of three years shows a marked seasonal breakage there also, but with this great difference that the maximum occurs in the winter time instead of the summer, as we find in watchsprings. In railroad rails we have a condition in which the crystal structure breaks down more rapidly in winter than in summer. It is not a fatigue phenomenon in the case of the watchsprings as is shown by the fact that the springs in the dry atmosphere are under the same tension as those in the saturated medium and yet only those in the moist air break.

If moisture is the chief agent in the seasonal breakage of watch mainsprings, are there any means whereby moisture may be prevented from getting in contact with springs? This would be a preventative measure against breakage. Positive results would also confirm the point of view that moisture was the main cause of the breakage. Oil is a means whereby the springs might be protected from the moisture, so two groups of springs were set up in the frames as before, one group being

1Railway Age Gazette, p. 1337, June 14, 1912. 
oiled and the other as it came from the factory. Both were then placed in the same enclosure containing a saturated vapor. The results were as follows:

\begin{tabular}{cccccc} 
& \multicolumn{5}{c}{ Table 2.} \\
Exp. No. & Samples & Samples & Days under & No. broken & No. bioken \\
4 & clean. & oiled. & observation. & clean. & oiled \\
5 & 16 & 16 & 33 & 3 & 0 \\
& 15 & 15 & 12 & 15 & 7
\end{tabular}

Experiment 4 was made on a new spring fresh from the factory while experiment 5 was an old spring which had been lying around in the laboratory and showed rust spots before being oiled. It is quite evident how efficacious the oil is in protecting the springs. It would indicate that jewelers might profitably run a campaign of preventative treatment of watchsprings, where an ounce of prevention would be worth a pound of cure.

It must be borne in mind that not all mainsprings which break are caused to do so by moisture. Some break because of mechanical imperfections. These mechanical imperfections are being picked out by magnetic means here in this laboratory in the hope that we shall be able, by starting with mechanically perfect watchsprings, to reduce the breakage to a minimum by keeping the springs free from moisture.

If one could study the mainspring breakage per capita in different parts of the country it doubtless would be found that the number would be smaller in dry sections than in the humid portions.

The author takes this opportunity of thanking most heartily those jewelers who have so kindly placed at our disposal their records of mainspring replacements.

TEST OF A VARIABLE IMMERSION HYDROMETER.

By PaUi, F. Gaehr,

Wells College, Aurora, N. Y.

In testing such a hydrometer, the simplest procedure is to have a series of stock solutions, whose densities have been accurately measured. This method is very simple for laboratories in which a great deal of this work goes on; but even there, the densities of the solutions is apt to vary on account of evaporation. In the High School laboratory, or the average college laboratory, the storage of a number of stock solutions is usually inconvenient. I have therefore devised an experiment which is capable of great accuracy, and which also helps the student to a better understanding of Archimedes' Law; 